\title{
Iodine release and antibacterial effects of a wound paste combined with PVP-iodine powder and/or solution in vitro
}

\author{
Mark Krämer, ${ }^{1,2}$, Philipp Sahrmann ${ }^{2}$, Beatrice Sener ${ }^{2}$, Thomas Thurnheer ${ }^{3}$, Thomas Attin ${ }^{2}$ and \\ Patrick R. Schmidlin ${ }^{2 *}$ \\ ${ }^{I}$ Private Praxis, Langnau am Albis, Switzerland \\ ${ }^{2}$ Clinic of Preventive Dentistry, Periodontology and Cariology, Center of Dental Medicine, University of Zurich, Switzerland \\ ${ }^{3}$ Institute of Oral Biology, Oral Microbiology and Immunology, Center of Dental Medicine, University of Zurich, Switzerland \\ *Corresponding author Email: patrick.schmidlin@zzm.uzh.ch
}

\begin{abstract}
Improvements of the substantivity of antibacterial agents in periodontal pockets during active therapy is still a challenge. With this study, the improved release kinetics of PVP-iodine by simply creating mixtures of a PVP-iodine solution and powder incorporated in different concentrations into a commercially available wound paste was investigated.

Iodine concentrations released by different formulations were determined by a titration method and the antibacterial effect was investigated using an agar diffusion method assessing the inhibition zone of two representative periopathogenic bacteria (Aggregatibacter actinomycetemcomitans and Porphyromonas gingivalis).

A prolonged release kinetic with up to one third of iodine released after one hour and even an ongoing release up to 4 hours was shown. The cumulative concentrations in the immersion solutions were sufficiently high to effectively inhibit bacterial growth in the agar test. The $\mathrm{pH}$ of the different mixtures was adequately buffered when tested in SBF as immersion medium, but resulted in acidic conditions when water was used.

Simple mixing of PVP-powder to an available wound paste may offer an easy method to prepare antibacterial products in-office with a potential pocket disinfection duration during the scaling and root planning appointment. Nevertheless, its therapeutic usefulness under clinical conditions needs further investigation and potential side-effects require clarification.
\end{abstract}

Keywords: Antimicrobial agents, iodine, laboratory investigation, periodontitis, slow release

\section{Introduction}

The treatment of periodontitis focuses on the effective reduction of bacterial contamination on tooth surfaces and adjacent tissues [1]. The removal of hard and soft deposits, i.e. calculus, plaque or biofilm, is conventionally achieved by mechanical means. However, any adjunctive dissolving or antibacterial action would be desirable as the pursued complete instrumentation - especially of deep lesions in teeth with complex anatomical features - is impossible to achieve [2]. Therefore, a complete non-surgical resolution of deeper pockets is unrealistic in most cases and persisting problems are based on an ongoing residual bacterial challenge [3].

To improve the efficacy of non-surgical periodontal therapy, several options are available to additionally remove the bacterial remnants mainly by chemical (antiseptics and antibiotics) or physical (lasers or air-polishing) means [4-6]. The latter, unfortunately, still have the disadvantage of relying on the adequate access with the tip to reach the affected sites, which may hamper or reduce its efficacy similar to conventional scaling devices [7,8]. Whereas the use of systemically administered antibiotics is very effective, the risk of resistance formation and systemic side-effects may limit their routine use [9, 10]. Therefore, locally applied antiseptics are a valuable alternative [11]. They are cheap, easy to use by irrigation syringe application, have less side-effects and produce no bacterial resistance [12]. However, a universally applicable and highly effective formulation has not been identified so far and products are not available on the market apart from gels and solutions. As an antibacterial agent, chlorhexidine has been widely used, but the clinical efficiency is questionable as an adjunct to scaling and root planning in the available formulations [13].

PVP-iodine could be a candidate as it represents an antiseptic with a broad antibacterial spectrum covering Grampositive and -negative bacteria and mycobacteria, [14] Staphylococcus spp., Candida albicans [15] and periopathogenic 
germs. [16, 17]. A systematic review focussing on PVP-iodine as an adjunct to scaling and root planning proved evidence for an improved therapeutic effect regarding pocket depth reduction [18]. The clinical benefit however is still smaller as compared to systemic antibiotics or surgical interventions. Due to gingival crevicular fluid flow and bleeding from the pockets, the concentration of the active agent applied in the form of solutions and its time of action is too small in most studies. Thus, there is still a need to search for a higher substantivity of drugs that aim to disinfect periodontal pockets with adequate antibacterial performance at least during the treatment time. One approach is to apply ointments. Only one study evaluated the clearance of PVP-iodine delivered as solution or ointment in periodontal pockets and showed indeed that the application of PVP-iodine ointment in periodontal pockets allows a prolonged remnant effect as compared to the use of a solution when applied to sites without previous instrumentation. The mean concentrations of the gel and solution were small, accounting for $6.14 \mu \mathrm{g} / \mathrm{ml}$ and $4.44 \mu \mathrm{g} / \mathrm{ml}(1 \mathrm{~min} ; \leq 0.028), 3.20 \mu \mathrm{g} / \mathrm{ml}$ and $1.44 \mu \mathrm{g} / \mathrm{ml}$ (5 $\mathrm{min} ; \geq 0.126), 0.69 \mu \mathrm{g} / \mathrm{ml}$ and $0.23 \mu \mathrm{g} / \mathrm{ml}$ (15 $\mathrm{min} ; \mathrm{p} \leq 0.019)$, respectively. Not surprisingly, in the pockets with previous debridement, the mean concentration even decreased significantly due to bleeding from the pocket [19]. Therefore, the ointment may offer some advantages over a solution, but improved pharmaceutical forms should be envisaged.

Therefore, this study assessed in a first part the release of iodine resulting from mixtures of either a PVP-iodine solution or PVP-iodine powder incorporated into a commercially available wound paste of different compositions. Our hypothesis was that this approach would result in a prolonged iodine release of at least two hours with adequate antibacterial concentrations during treatment time. In the second part of the study the antibacterial effect of different concentrations of PVP-iodine were screened using an agar diffusion method assessing two representative periopathogenic bacteria.

\section{Methods}

\subsection{Iodine release}

Pure compounds and mixtures of a commercially available wound paste (Solcoseryl ${ }^{\circledR}$ Dental-Adhäsivpaste; Meda Pharma, Brütisellen, Switzerland) with PVP-iodine solution (Betadine, Mundipharma, Basel, Switzerland) and/or a PVP-iodine powder (30/06, BASF Burgbernheim, Germany) were prepared according to Table 1.

Table 1: Iodine content in the respective formulations and mixtures.

\begin{tabular}{lcc}
\hline & \multicolumn{1}{l}{ Iodine content } \\
\cline { 2 - 3 } Compounds & $\begin{array}{c}\text { mg per } \\
\text { g material }\end{array}$ & \% of the material \\
\hline Wound paste (WP) & 0 & 0 \\
\hline PVP-iodine powder (P) & 108.4 & 10.8 \\
\hline PVP-iodine solution (S) & 7.8 & 0.8 \\
\hline Mixtures & 56.5 & 5.7 \\
\hline WP:P:S $=1: 1: 0$ & 3.9 & 0.4 \\
\hline WP:P:S $=1: 0: 1$ & 40.2 & 4.0 \\
\hline WP:P:S $=1: 1: 1$ & 32.1 & 3.2 \\
\hline WP:P:S $=1: 1: 2$ & 58.4 & 5.8 \\
\hline WP:P:S $=1: 2: 1$ & &
\end{tabular}

The compounds were weighed on a high precision scale and thoroughly mixed on a sterile glass plate subsequently. One gram of the resulting product was then taken and transferred to a custom-made mesh made of stainless steel $(0.1 \mathrm{~mm}$, inner width $1 \mathrm{~mm}$, Figure 1).

This procedure allowed for a paste stabilization, quick removal and transport between the different vials during the immersion process while providing adequate contact of the material to the liquid. The paste mixtures were immersed for $5,10,15,30,60,120,180$ and 240 minutes at $37^{\circ} \mathrm{C}$ under constant motion in $10 \mathrm{~mL}$ simulated body fluid (SBF), which was prepared by dissolving reagent chemicals of $\mathrm{NaCl}, \mathrm{NaHCO} 3, \mathrm{KCl}, \mathrm{K} 2 \mathrm{HPO}_{4} \times 3 \mathrm{H}_{2} \mathrm{O}, \mathrm{MgCl}_{2} \times 6 \mathrm{H}_{2} \mathrm{O}, \mathrm{CaCl}_{2}$ and $\mathrm{Na}_{2} \mathrm{SO}_{4}$ in ion-exchanged water. The ion concentrations of $\mathrm{SBF}$ in $\mathrm{mM}$ was: $\mathrm{Na}^{+} 142.0, \mathrm{~K}^{+} 5.0, \mathrm{Mg}^{2+} 1.5, \mathrm{Ca}^{2+} 2.5, \mathrm{Ca}^{-}$ 147.8, $\mathrm{HCO}_{3}{ }^{-} 4.2, \mathrm{HPO}_{4}{ }^{2-} 1.0, \mathrm{SO}_{4}{ }^{2-} 0.5$, respectively. The solution was buffered at physiological $\mathrm{pH} 7.4\left(37^{\circ} \mathrm{C}\right)$ with tris(hydroxymethylaminomethane) and hydrochloric acid. After each time period, the liquid was collected and the test paste was transferred together with the mesh into a new vial. All materials were prepared, stored and measured in 
triplicates.

The iodine determination of each sample was done in two aliquot extracts. The solutions were titrated according to a compendial method (Povidone iodine, Ph.Eur., $7^{\text {th }}$ Edition, 2012), which involved titration of aqueous solution against a standardized sodium thiosulphate solution using starch as indicator.

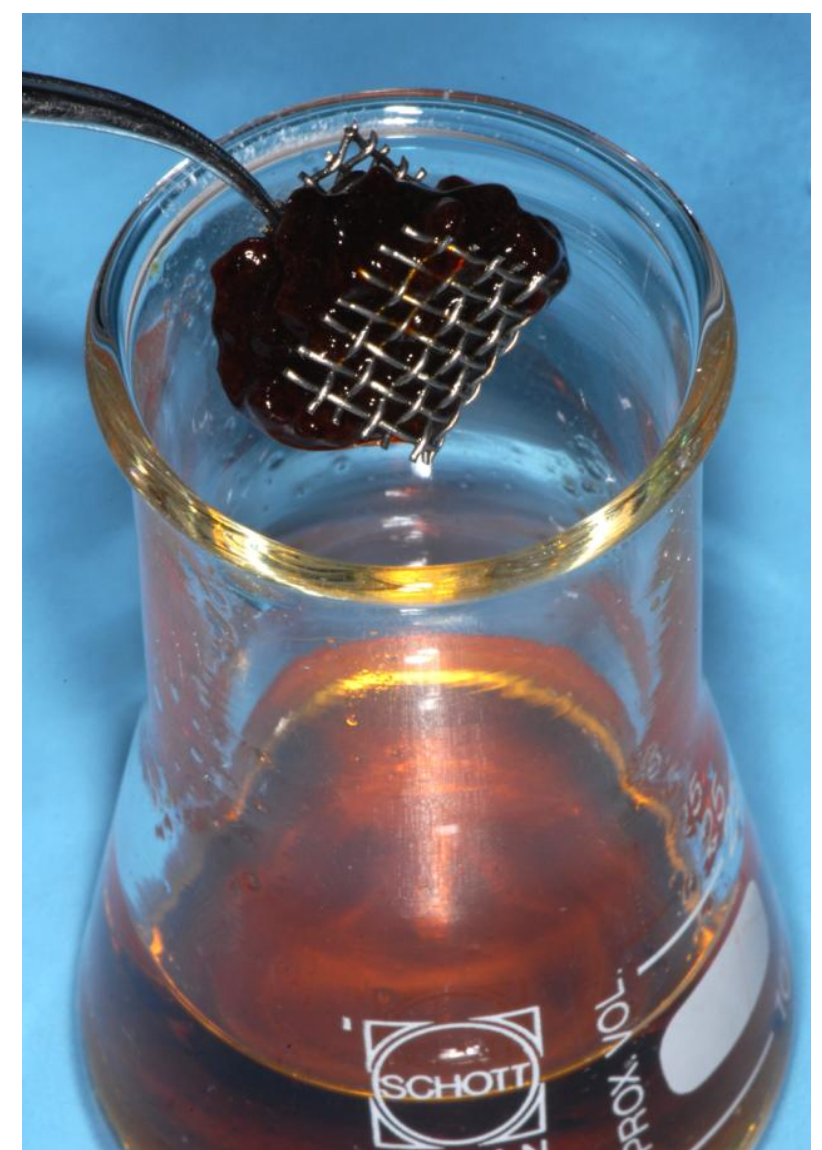

Fig. 1: Illustration of the custom-made mesh made of stainless steel, which served for material transfer and stable immersion.

\subsection{Agar diffusion test}

To study the antibacterial effects, aqueous solutions with concentrations corresponding to the PVP-iodine values determined in the first part of this study were prepared and tested on Porphyromonas gingivalis (OMZ 925) and Aggregatibacter actinomycetemcomitans (OMZ 299). For the inoculum the two strains were grown separately in fluid universal medium (FUM) (9). Towards the end of the exponential growth phase the optical density of the cell suspensions was measured at a wavelength of $550 \mathrm{~nm}$ and adjusted by dilution with FUM to an optical density of 1.0. Columbia Blood Agar (CBA) without addition of blood (Becton Dickinson Microbiology Systems, Sparks, MD, USA) was prepared according to the manufacturer's instructions. The agar was kept in a waterbath at $50^{\circ} \mathrm{C}$ until further use. For each strain Petri dishes were prepared by mixing $20 \mathrm{ml}$ of agar with $1 \mathrm{ml}$ of the corresponding inoculum. After solidification of the culture medium wells measuring $5 \mathrm{~mm}$ in diameter were punched out. These cavities were then filled with solutions of different PVP-iodine concentrations. These concentrations correlated with those obtained from the release trial of the first part of the study. The iodine solutions were composed by mixing PVP powder with SBF. Chlorhexidine $(0.2 \%)$ and SBF alone were used as control media. After $48 \mathrm{~h}$ of anaerobic incubation at $37^{\circ} \mathrm{C}$, the zones of inhibition were measured using a caliper. The experiments were performed in triplicates.

\section{$2.3 \mathrm{pH}$ measurement}

In addition, the $\mathrm{pH}$ of the solutions was measured in triplicates using a $\mathrm{pH}$ electrode (Metrohm, Zofingen, Switzerland) up to 4 hours until the $\mathrm{pH}$ was stable or the paste or material had been completely dissolved. In accordance, materials were immersed in either water of SBF at $37^{\circ} \mathrm{C}$. 


\subsection{Data presentation and statistical analyses}

Mean values and standard deviations of the iodine release in mg and expressed as percentage of the tested compound were calculated and presented in a table over time. At each time point, results of were compared using ANOVA and individual post hoc comparisons were performed using a Student's $t$-test followed by Bonferroni correction for multiple comparisons. Significance was set at $95 \%(\mathrm{p} \leq 0.05)$.

Diameters of zones of inhibition were presented for each measurement individually in a bar chart and mean values of the $\mathrm{pH}$ measurements were reported by a simple descriptive table.

\section{Results}

Whereas the theoretical iodine content is presented in Table 1, the iodine measurements after immersion for up to 4 hours are depicted in Table 2.

Table 2: Iodine content in the respective formulations and mixtures at different evaluation times. Statistical comparison was made between different mixtures and different superscript capitals represent values, which are statistically significantly different $(\mathrm{P}>0.05)$. Mixtures indicated with the same superscript capitals represent iodine content values, which are not statistically significant different at a specific time point (read vertically; ANOVA, Bonferroni/Dunn correction).

\begin{tabular}{|c|c|c|c|c|c|c|c|c|}
\hline & & 51 & $10 '$ & $15^{\prime}$ & 30' & $60^{\prime}$ & $120 '$ & $240^{\prime}$ \\
\hline \multirow{2}{*}{ Wound paste (WS) } & mg & $\mathbf{0} \pm 0$ & $\mathbf{0} \pm 0$ & $\mathbf{0} \pm 0$ & $\mathbf{0} \pm 0$ & $\mathbf{0} \pm 0$ & $\mathbf{0} \pm \mathbf{0}$ & $\mathbf{0} \pm 0$ \\
\hline & $\%$ & $0 \pm 0$ & $0 \pm 0$ & $0 \pm 0$ & $0 \pm 0$ & $0 \pm 0$ & $0 \pm 0$ & $0 \pm 0$ \\
\hline \multirow[t]{2}{*}{ PVP-iodine powder $(\mathrm{P})$} & mg & $97.9 \pm 0.3$ & $1.1 \pm 1.9$ & $1.8 \pm 1.6$ & $1.2 \pm 1.1$ & $0.7 \pm 1.1$ & & \\
\hline & $\%$ & $90.3 \pm 0.3$ & $1.0 \pm 1.7$ & $1.6 \pm 1.4$ & $1.1 \pm 1.0$ & $0.6 \pm 1.0$ & & \\
\hline PVP-iodine solution (S) & $\begin{array}{l}\mathbf{m g} \\
\%\end{array}$ & $\begin{array}{l}\mathbf{7 . 7} \pm \mathbf{0 . 2} \\
99.6 \pm 0.6\end{array}$ & & & & & & \\
\hline
\end{tabular}

\begin{tabular}{|c|c|c|c|c|c|c|c|c|}
\hline WP:P:S = 1:1:0 & $\underset{\%}{\mathbf{m g}}$ & $\begin{array}{l}6.1 \pm 2.9 \\
11.3 \pm 5.4\end{array}$ & $\begin{array}{l}\mathbf{3 . 6} \pm \mathbf{2 . 3} \mathbf{A C}^{\mathrm{AC}} \\
6.8 \pm 4.1\end{array}$ & $\begin{array}{l}\mathbf{3 . 4} \pm \mathbf{1 . 8} \\
6.1 \pm 3.4\end{array}$ & $\begin{array}{l}\mathbf{5 . 0} \pm \mathbf{1 . 6} \\
9.2 \pm 3.0\end{array}$ & $\begin{array}{l}7.4 \pm 1.1^{\mathbf{A}} \\
13.5 \pm 1.2\end{array}$ & $\begin{array}{l}\mathbf{1 0 . 7} \pm \mathbf{1 . 7}{ }^{\mathrm{A}} \\
19.7 \pm 3.0^{-}\end{array}$ & $\begin{array}{l}\mathbf{1 2 . 0} \pm \mathbf{0 . 9} \\
17.2 \pm 9.1\end{array}$ \\
\hline WP:P:S = 1:0:1 & $\begin{array}{l}\mathrm{mg} \\
\%\end{array}$ & $\begin{array}{l}\mathbf{0} \pm \mathbf{0} \\
0 \pm 0\end{array}$ & $\begin{array}{l}\mathbf{0} \pm \mathbf{0} \\
0 \pm 0\end{array}$ & $\begin{array}{ll}\mathbf{0} \pm \mathbf{0} & \text { B } \\
0 \pm 0 & \end{array}$ & $\begin{array}{l}\mathbf{0} \pm \mathbf{0} \\
0 \pm 0\end{array}$ & $\begin{array}{l}\mathbf{0} \pm \mathbf{0} \\
0 \pm 0\end{array}$ & $\begin{array}{l}\mathbf{0} \pm \mathbf{0} \\
0 \pm 0\end{array}$ & $\begin{array}{l}\mathbf{0} \pm \mathbf{0} \\
0 \pm 0\end{array}$ \\
\hline WP:P:S = 1:1:1 & mg & $\begin{array}{ll}\mathbf{1 . 3} \pm \mathbf{0 . 4} & \mathrm{BC} \\
3.3 \pm 0.9 & \end{array}$ & $\begin{array}{l}\mathbf{1 . 6} \pm \mathbf{0 . 3} \\
4.1 \pm 0.9\end{array}$ & $\begin{array}{l}\mathbf{1 . 5} \pm \mathbf{0 . 2} \\
4.1 \pm 0.6\end{array}$ & $\begin{array}{l}\mathbf{4 . 5} \pm 1.8 \\
9.7 \pm 1.0\end{array}$ & $\begin{array}{l}\mathbf{5 . 8} \pm 1.9 \\
14.4 \pm 3.8\end{array}$ & $\begin{array}{l}\mathbf{1 0 . 3} \pm \mathbf{1 . 0} \\
25.0 \pm 1.9\end{array}$ & $\begin{array}{l}\mathbf{1 1 . 4} \pm \mathbf{1 . 1} \\
26.1 \pm 4.1\end{array}$ \\
\hline WP:P:S = 1:1:2 & mg & $\begin{array}{ll}\mathbf{1 . 4} \pm \mathbf{0 . 4} & \mathrm{BC} \\
4.5 \pm 1.2 & \end{array}$ & $\begin{array}{l}\mathbf{1 . 4}^{\mathbf{4} \mathbf{0 . 3}}{ }^{\mathrm{B}} \\
4.6 \pm 0.9\end{array}$ & $\begin{array}{l}\mathbf{1 . 4} \pm \mathbf{0 . 1} \mathbf{B C}^{\mathbf{B C}} \\
4.5 \pm 0.2^{-5}\end{array}$ & $\begin{array}{l}\mathbf{3 . 3} \pm \mathbf{0 . 3} \mathbf{3}^{\mathbf{A}} \\
10.7 \pm 0.9\end{array}$ & $\begin{array}{l}5.2 \pm 0.4 \\
16.8 \pm 1.2\end{array}$ & $\begin{array}{l}7.1 \pm 0.6 \\
22.9 \pm 15.9\end{array}$ & $\begin{array}{l}\mathbf{6 . 2} \pm \mathbf{0 . 5} \\
15.9 \pm 8.1\end{array}$ \\
\hline WP:P:S = 1:2:1 & $\underset{\%}{\mathbf{m g}}$ & $\begin{array}{l}\mathbf{3 . 4} \pm \mathbf{0 . 4} \\
6.0 \pm 0.8\end{array}$ & $\begin{array}{l}\mathbf{3 . 6} \pm \mathbf{0 . 5}^{\mathbf{A}} \\
6.4 \pm 1.0\end{array}$ & $\begin{array}{l}3.4 \pm 0.3^{A} \\
6.0 \pm 0.6\end{array}$ & $\begin{array}{l}8.9 \pm 0.9 \\
15.9 \pm 1.6\end{array}$ & $\begin{array}{l}\mathbf{1 3 . 5} \pm \mathbf{0 . 7} \\
24.0 \pm 1.3\end{array}$ & $\begin{array}{l}\mathbf{1 5 . 2} \pm \mathbf{0 . 6} \\
27.0 \pm 1.1\end{array}$ & $\begin{array}{l}3.5 \pm 2.1 \\
4.9 \pm 2.6\end{array}$ \\
\hline
\end{tabular}

As expected, the wound paste contained no iodine in its original formulation, whereas the original PVP-iodine released almost its complete iodine content in the first minutes. Interestingly, a mixture of the wound paste with the PVP-iodine solution alone showed no iodine release. Only combinations with the powder were able to release iodine for a prolonged time period. Cumulatively, 35-60\% PVP-iodine was released from the pastes in the first hour. Overall, the powder/solution ratio influenced the iodine release. The highest iodine concentration in solution was detected for the mixture, in which more powder than solution had been added.

The solubility of the paste was greatly influenced by the buffer capacity of the immersion media, which was clearly shown in the $\mathrm{pH}$ measurements. Materials subjected to water immersion resulted in acidic dissolution patterns (Table 3).

All mixtures with iodine powder resulted in $\mathrm{pH}$ values close to or below 4.5 within the first five minutes, which can be explained by the very acidic dissolution of the powder in water alone. Only the mixture without powder addition exhibited a comparable $\mathrm{pH}$ decrease like the wound paste. All mixed compositions were completely dissolved in water after 60 minutes. In contrast, immersion in SBF showed a $\mathrm{pH}$ neutral dissolution of the wound paste and a less acidic behavior of the pure iodine compounds (Table 4). 
Table 3: Measurements of $\mathrm{pH}$ of the original components and mixtures after immersion in water for up to 4 hours (green: neutral pH-range; blue: basic $\mathrm{pH}$-range, yellow-red-purple: acidic $\mathrm{pH}$ range; grey: not measurable, material dissolved)

\begin{tabular}{|c|c|c|c|c|c|c|c|c|}
\hline & $0^{6}$ & $5^{\prime}$ & $10^{\prime}$ & $15^{\prime}$ & 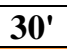 & $60^{\prime}$ & $120^{\prime}$ & $240^{\prime}$ \\
\hline Wound paste (WP) & 9.1 & 7.6 & 6.7 & 6.0 & 5.4 & 5.1 & 5.0 & 4.8 \\
\hline PVP-iodine powder (P) & & 2.1 & 2.0 & 2.0 & 1.9 & & & \\
\hline PVP-iodine solution (S) & 5.8 & & & & & & & \\
\hline WP:P:S = 1:1:0 & 7.0 & 3.7 & 3.7 & 3.6 & 3.3 & & & \\
\hline WP:P:S = 1:0:1 & 9.4 & 6.2 & 5.4 & 5.2 & 5.0 & 4.8 & & \\
\hline WP:P:S = 1:1:1 & 6.7 & 4.4 & 4.4 & 4.5 & 4.2 & & & \\
\hline WP:P:S = 1:1:2 & 8.3 & 4.4 & 4.3 & 3.8 & 3.6 & 3.6 & & \\
\hline WP:P:S = 1:2:1 & 7.1 & 3.3 & 3.2 & 3.2 & 3.2 & 3.2 & & \\
\hline
\end{tabular}

Table 4: Measurements of $\mathrm{pH}$ of the original components and mixtures after immersion in SBF for up to 4 hours (green: neutral pH-range; blue: basic $\mathrm{pH}$-range, yellow-red-purple: acidic $\mathrm{pH}$ range; grey: not measurable, material dissolved).

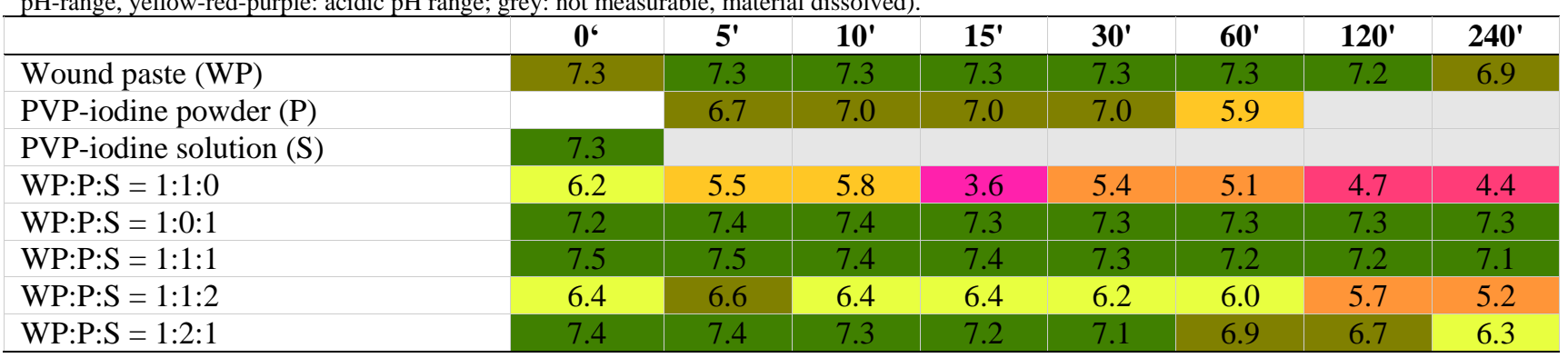

Only the mixture with the powder alone showed $\mathrm{pH}$ values below 5 after 2 hours. Paste mixtures were more resistant to a pH decrease and more stable. None of the pastes was completely dissolved after the whole observation period. The antibacterial activity of PVP-solutions is shown in Figures 2 and 3.

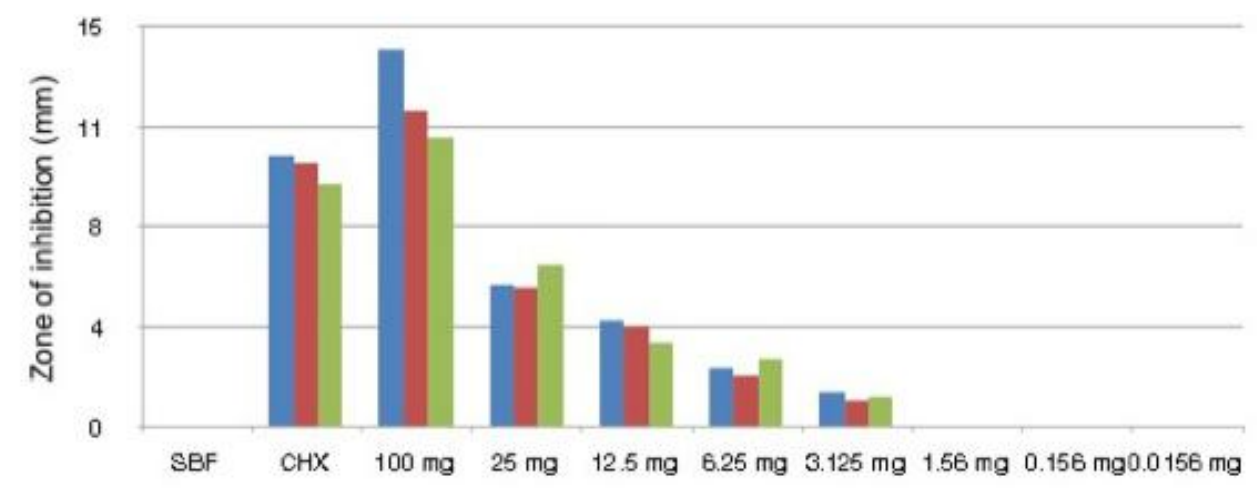

Fig. 2: Antibacterial effect against $P$. gingivalis assessed by agar diffusion method depicted as three individual measurements as inhibition zones in $\mathrm{mm}(\mathrm{SBF}=$ simulated body fluid; $\mathrm{CHX}=$ chlorhexidine $0.2 \%$; tested PVP-iodine concentrations).

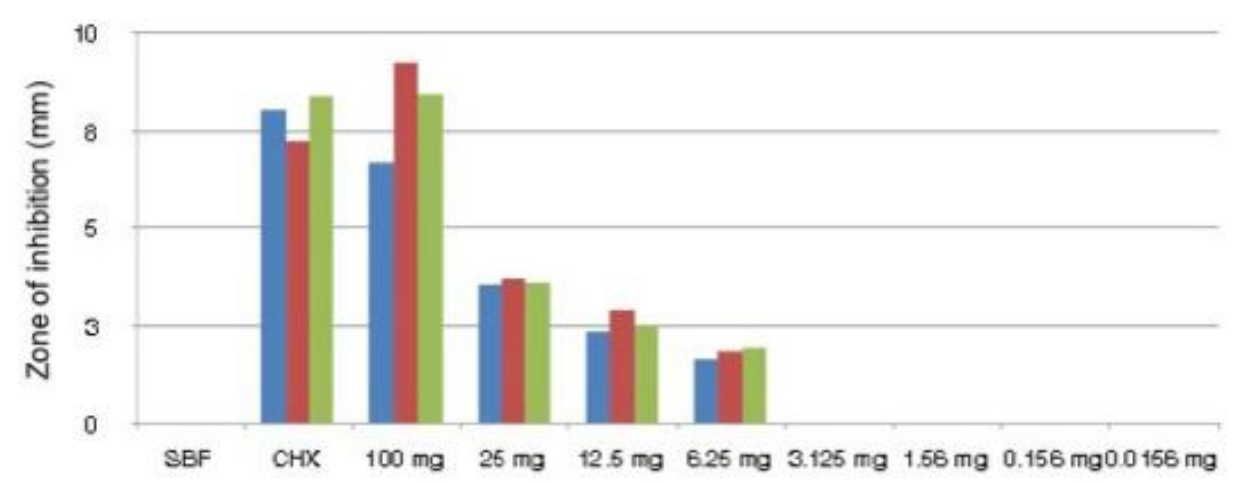

Fig. 3: Antibacterial effect against A. actinomycetemcomitans serotype b assessed by agar diffusion method depicted as three individual measurements as inhibition zones in $\mathrm{mm}(\mathrm{SBF}=$ simulated body fluid; $\mathrm{CHX}=$ chlorhexidine $0.2 \%$; tested $\mathrm{PVP}$-iodine concentrations). 
Clear zones of inhibition could be detected for A. actinomycetmcomitans and P. gingivalis for concentrations up to 6.25 and $3.125 \mathrm{mg}$, respectively. Below these concentrations, no inhibition zones were noted. A dose-dependent decrease in effectiveness was observed with decreasing concentrations.

\section{Discussion}

This study revealed a prolonged release of iodine if mixed with a commercially available wound paste for a time period of up to 4 hours. Hereby, iodine concentrations of more than $1.0 \mathrm{mg} / \mathrm{ml}$ were found. Accordingly our hypothesis has been confirmed.

In a recent clinical study, the clearance of PVP-iodine applied as a gel or solution was investigated in periodontal pockets [19]. The mean concentrations of the gel and solution, however, were much lower as compared to the results of the present study. Furthermore, concentrations decreased rapidly under clinical conditions within the first 15 minutes. They accounted for $6.1 \mu \mathrm{g} / \mathrm{ml}$ and $4.4 \mu \mathrm{g} / \mathrm{ml}$ after $1 \mathrm{~min}, 3.2 \mu \mathrm{g} / \mathrm{ml}$ and $1.4 \mu \mathrm{g} / \mathrm{ml}$ after $5 \mathrm{~min}$ and $0.7 \mu \mathrm{g} / \mathrm{ml}$ and 0.2 $\mu \mathrm{g} / \mathrm{ml}$ after $15 \mathrm{~min}$, respectively. In the pockets with previous debridement the mean concentration was even lower after 1 minute $(1.7 \pm 2.0 \mu \mathrm{g} / \mathrm{ml})$. Despite the conclusion that the application of PVP-iodine gel in periodontal pockets allowed for prolonged remnant effect as compared to that of the solution formula, other alternatives with slower release and higher iodine concentrations are still warranted. In the present study, we were able to create an iodine release with concentrations in the range of more than $1 \mathrm{mg} / \mathrm{ml}$. However, concentrations lower than $6.25 \mathrm{mg} / \mathrm{ml}$ failed to be effective in killing the bacteria under the conditions of this investigation. However, studies of Higashitsutsumi et al. and Gocke et al. $[15,20]$ showed that PVP-iodine at very low concentrations is able to eliminate periodontal pathogens. Those studies, however, used a planktonic antibacterial assay in vitro. Schreier and co-workers found that even lower PVPiodine concentrations resulted in an efficacy maximum against Staphylococcus aureus, Candida albicans and Escherichia coli under laboratory conditions [14]. Yet, bacteria imbedded in the biofilm with its protective and adhesive extracellular matrix are much less susceptible to antiseptics [21, 22]. Nevertheless, PVP-iodine as a iodophor with a broad antibacterial spectrum, low potency for developing adverse reactions and low financial cost remains a valuable alternative that is free from the risk of developing bacterial resistance [23]. Furthermore, its utility has also been reported in non-surgical periodontal therapy [2, 23-25].

Since antiseptics, unlike antibiotics, are potentially toxic to both infectious and host cells, their application in humans is limited to infected wounds of skin and mucosa. Like other antiseptics, PVP-iodine has a nonselective mechanism of action, and the high concentrations used in the oral cavity may adversely affect the host cells. In vitro studies have already reported deleterious effects on fibroblasts and osteoblasts [26, 27]. The latter study has shown that 5 and $10 \%$ PVP-iodine caused cell death of host fibroblasts within minutes and that contact with $1 \%$ PVP-iodine resulted in a loss of the characteristic elongated cell shape. A previous study has assessed this aspect [28]. This study has shown that a short-time application of PVP-iodine in concentrations of 1:10 and higher lead to decreased viability and impaired differentiation. However, surviving cells showed good recovery and even a great mineralization potential. If this is the case with longer application at high doses has not been assessed yet and should be taken into consideration as well. The wound paste at least showed a good buffering capacity of the mixtures, which may reduce any tissue damage due to acidic conditions.

\section{Conclusions}

Within the limitations of this study, we conclude, that with a simple mixture of PVP-iodine powder together with a commercially available wound paste a prolonged release up to 4 hours of iodine can be achieved, which has an antibacterial effect. As a matter of course, the proposed mixture must yet prove both clinical innocuousness and efficacy before application in patients can be considered.

\section{References}

[1] G. Greenstein, Nonsurgical periodontal therapy in 2000: a literature review. Journal of the American Dental Association 131 (2000) 15801592.

[2] J. Slots, Selection of antimicrobial agents in periodontal therapy. Journal of Periodontal Research 37 (2002) $389-398$.

[3] G. Greenstein, Position paper: The role of supra- and subgingival irrigation in the treatment of periodontal diseases. Journal of Periodontology 76 (2005) 2015-2027.

[4] I. Darby, Non-surgical management of periodontal disease. Australian Dental Journal 54 (2009) S86-95.

[5] C.M. Cobb, S.B. Low, D.J. Coluzzi, Lasers and the treatment of chronic periodontitis. Dental Clinics of North America 54 (2010) $35-53$. 
[6] R. Moene, F. Decaillet, E. Andersen, A. Mombelli, Subgingival plaque removal using a new air-polishing device. Journal of Periodontology 81 (2010) 79-88.

[7] F. Sgolastra, M. Severino, R. Gatto, A. Monaco A, Effectiveness of diode laser as adjunctive therapy to scaling root planning in the treatment of chronic periodontitis: a meta-analysis. Lasers in Medical Science 2012 (in press)

[8] P. Sahrmann, V. Ronay, B. Sener, R.E. Jung, T. Attin, P.R. Schmidlin, Cleaning potential of glycine air-flow application in an in vitro periimplantitis model. Clin Oral Implants Res, 2012 (in press)

[9] A. C. Veloo, K. Seme, E. Raangs, P. Rurenga, Z. Singadji, G. Wekema-Mulder, A.J. van Winkelhoff, Antibiotic susceptibility profiles of oral pathogens. International Journal of Antimicrobial Agents 40 (2012) 450-454.

[10] A. Mombelli, L.P. Samaranayake, Topical and systemic antibiotics in the management of periodontal diseases. International Journal of Dentistry 54 (2004) 3-14.

[11] J. Cosyn, I. Wyn, T. De Rouck, M.M. Sabzevar, Subgingival chlorhexidine varnish administration as an adjunct to same-day full-mouth root planing. I. Clinical observations. Journal of Periodontology 78 (2007) 430-437.

[12] M.G. Jorgensen, A. Aalam, J. Slots J. Periodontal antimicrobials--finding the right solutions. International Dental Journal 55 (2005) 3-12.

[13] A.J. Bonito, L. Lux, K.N. Lohr, Impact of local adjuncts to scaling and root planing in periodontal disease therapy: a systematic review. Journal of Periodontology 76 (2005) 1227-1236.

[14] H. Schreier, G. Erdos, K. Reimer, B. Konig, W. Konig, W. Fleischer, Molecular effects of povidone-iodine on relevant microorganisms: an electron-microscopic and biochemical study. Dermatology 195 (1997) Suppl 2: 111-116.

[15] D.J. Gocke, S. Ponticas, W. Pollack, In vitro studies of the killing of clinical isolates by povidone-iodine solutions. Journal of Hospital Infections 6 (1985) Suppl A: 59-66.

[16] C.L. Drisko, D.L. Cochran, T. Blieden, O.J. Bouwsma, R.E. Cohen, P. Damoulis et al., Position paper: sonic and ultrasonic scalers in periodontics. Research, Science and Therapy Committee of the American Academy of Periodontology. Journal of Periodontology 71 (2000) 1792-1801.

[17] P.W. Caufield, D.N. Allen, N.K. Childers, In vitro susceptibilities of suspected periodontopathic anaerobes as determined by membrane transfer assay. Antimicrobial Agents and Chemotherapeutics 31 (1987) 1989-1993.

[18] P. Sahrmann, M.A. Puhan, T. Attin, P.R. Schmidlin, Systematic review on the effect of rinsing with povidone-iodine during nonsurgical periodontal therapy. Journal or Periodontal Researchal Res 45 (2009) 153-164.

[19] P. Sahrmann, B. Sener, V. Ronay, T. Attin, P.R. Schmidlin, Clearance of topically-applied PVP-iodine as a solution or gel in periodontal pockets in men. Acta Odontologica Scandinavica 70 (2012) 497-503.

[20] M. Higashitsutsumi, K. Kamoi, H. Miyata, S. Ohgi, T. Shimizu, K. Koide et al., Bactericidal effects of povidone-iodine solution to oral pathogenic bacteria in vitro. Postgraduate Medical Journal 69 (1993) Suppl 3: S10-4.

[21] R.L. Anderson, R.W. Vess, A.L. Panliliom M.S. Favero MS, Prolonged survival of Pseudomonas cepacia in commercially manufactured povidone-iodine. Applied Environmental Microbiology 56 (1990) 3598-3600.

[22] V. Zijnge, M.B. van Leeuwen, J.E. Degener, F. Abbas, T. Thurnheer, R. Gmur, J. Harmsen, Oral biofilm architecture on natural teeth. PLoS One 5 (2010) e9321.

[23] G. Greenstein, Povidone-iodine's effects and role in the management of periodontal diseases: a review. Journal of Periodontology 70 (1999) 1397-1405.

[24] B. Rosling, M.K. Hellstrom, P. Ramberg, S.S. Socransky, J. Lindhe, The use of PVP-iodine as an adjunct to non-surgical treatment of chronic periodontitis. Journal of Clinical Periodontology 28 ( 2001) 1023-1031.

[25] T. Hoang, M.G. Jorgensen, R.G. Keim, A.M. Pattison, J. Slots, Povidone-iodine as a periodontal pocket disinfectant. Journal of Periodontal Research 38 (2003) 311-317.

[26] R. Wilken, S.J. Botha, A. Grobler, P.J. Germishuys, In vitro cytotoxicity of chlorhexidine gluconate, benzydamine-HCl and povidone iodine mouthrinses on human gingival fibroblasts. Saudi Arabian Dental Journal 56 (2001) 455-460.

[27] C.T. Cabral, M.H. Fernandes, In vitro comparison of chlorhexidine and povidone-iodine on the long-term proliferation and functional activity of human alveolar bone cells. Clinical Oral Investigations 11 (2007) 155-164.

[28] P.R. Schmidlin, T. Imfeld, P. Sahrmann, A. Tchouboukov, F.E. Weber, Effect of short-time povidone-iodine application on osteoblast proliferation and differentiation. Open Dentistry Journal 3 (2009) 208-212. 